\section{They come for the fiction and stay for the science}

As one of the earliest participants in the Science and Entertainment Exchange Program of the US National Academy of Sciences, I would like to counter Daniel Sarewitz's criticisms (Nature 466,$27 ; 2010$ ) by highlighting its success in promoting science to the public.

The Exchange was set up in 2008 in response to Hollywood's demand for scientific advice. True to its name, it also provides a boost for science by stimulating the audience's interest in scientific topics through the resulting film or television programme.

I worked as a physics consultant on the 2009 film Watchmen and on a video discussing the science behind it. The video intercut scenes from the film with a discussion of the physics of wave interference and an experimental demonstration of electron diffraction. It was posted on several websites, including Ain't It Cool News and Pharyngula, as well as on blogs run by Richard Dawkins and film critic Roger Ebert.

Within a few months, the video had been watched more than 1.5 million times. I could teach 1,000 students a year for 15 centuries before I would reach that many people. I doubt that I could get even 15 people to view a straightforward video demonstrating the wave-particle duality that underlies quantum physics. But, by tying the facts to a major motion picture, people who came for the fiction stayed for the science.

Fans of fantastic fiction are excited by cool ideas, especially if they turn out to be true. The Exchange programme helps to feed that excitement, providing an opportunity to connect scientists to people they would not normally reach.

This spring, more than 14 million people (many of whom are registered voters) watched an episode of the CBS comedy The Big Bang Theory. It featured a scene in which a group of physics and astronomy PhDs sets up a powerful laser on the roof of their apartment to bounce a signal from the reflectors placed on the Moon by the Apollo astronauts. The group is jubilant about the trace on an oscilloscope screen because it relays evidence of man-made objects on the Moon, "put there by a member of a species that only 60 years before had just invented the airplane".

Such examples are a testament to the value of the Science and Entertainment Exchange's efforts to promote science awareness.

James Kakalios School of Physics and Astronomy, The University of Minnesota, 116 Church Street S.E., Minneapolis, Minnesota 55455, USA e-mail:kakalios@umn.edu

\section{Businesses and biodiversity: they would say that}

Ricardo Bayon and Michael Jenkins's Opinion article oversimplifies the role of business in addressing environmental issues (Nature 466, 184-185; 2010).

Biodiversity interacts with essential and interdependent planetary processes, such as climate change and nitrogen cycles, which are already approaching threshold limits (Nature 461, 472-475; 2009). Bayon and Jenkins's view of existing market-based mechanisms - for example, the European Union (EU) carbon market and biodiversity offsets - is too narrow. The EU Emission Trading Scheme may even allow heavy carbon polluters to receive windfall profits through intense corporate lobbying, without reducing emissions (A. G. Hopwood Account. Org. Soc. 34, 433-439, 2009).
Governments are looking at economic valuation as a way to help solve environmental problems. Although this approach may catch the attention of business leaders, there are still difficulties - including how to price complex natural services such as biodiversity adequately.

Proper valuation requires accurate, transparent information. Roldan Muradian and colleagues have concluded that most valuations "are characterized by incomplete information, particularly regarding the relationship between ecosystems, human interventions and the provision of environmental services" (R. Muradian et al. Ecol. Econ. 69, 1202-1208; 2010). Market-based solutions also require, but rarely incorporate, ongoing monitoring of performance.

The economic valuation of ecosystem services overrides local rules of governance and does not address power inequities or poverty. Elite groups tend to be the main beneficiaries of such schemes, which can exacerbate inequities in countries such as Madagascar (M. Sommerville et al. Ecol. Econ. 69, 1262-1271; 2010). Indigenous peoples in the United States, Canada, Australia, New Zealand and elsewhere continue to fight for land rights and for consultation on the development of natural resources.

Bayon is co-founder of a firm that sells biodiversity offsets and other commercial products. The role of such intermediaries is rarely studied, but is crucial because they determine which ecosystem services are to be traded and influence pricing and social acceptance.

A wholesale redesign of the global economic system is not hard to imagine, as Bayon and Jenkins suggest. It is precisely what is required.

Gail Whiteman Department of Business Society Management, Rotterdam School of Management, Erasmus University Rotterdam, 3000 DR, The Netherlands e-mail: gwhiteman@rsm.nl

Michael Dorsey Environmental Studies Program, 6182 Steele Hall, Dartmouth College, Hanover, New Hampshire 03755, USA

Bettina Wittneben Smith School of Enterprise and the Environment, University of Oxford, 75 George Street, Oxford OX12BQ, UK

\section{An independent thinker, willing to say what he thought}

We object to the inaccurate and misleading characterization of William Nierenberg by Naomi Oreskes and Erik Conway (Nature 465, 686-687; 2010). Their claim that the peer-review panel chaired by Nierenberg "played down the severity of acid rain" is a contradiction of the panel report itself (see W. A. Nierenberg, chairman, Report of the Acid Rain Peer Review Panel; White House Office of Science and Technology Policy, 1984).

Commenting on an interim version of this report, The New York Times wrote on 27 June 1983 that it "concludes that action should be taken immediately to curb acid rain ... It is the first recommendation by an official Government panel calling for action and not just more study to deal with acid rain, according to William A. Nierenberg."

Nierenberg, who died in September 2000, was an independent thinker who was always willing to say what he thought, regardless of what was popular or expected. He knew that building public support for science begins with a constant regard for the truth.

Nicolas Nierenberg Nierenberg Foundation, 9494 La Jolla Farms Road, La Jolla, California 92037, USA e-mail: nicolasnierenberg@gmail.com Walter R. Tschinkel Department of Biological Science, Florida State University, Tallahassee, Florida 323064370, USA

Victoria J. Tschinkel 1561 Marion Avenue, Tallahassee, Florida 323145948, USA 